\title{
Reply to McDonald and colleagues: "Can endoscopic ultrasound- guided gastroenterostomy be used as first line modality for endoscopic management of malignant gastric outlet obstruction?"
}

We would like to thank Dr. McDonald and colleagues for their comments on our manuscript "Patency of endoscopic ultrasound-guided gastroenterostomy in the treatment of malignant gastric outlet obstruction" [1]. The authors raised several points, the first of which was regarding issues about the higher adverse event $(A E)$ rate reported in our series compared with previous reports: 1) whether these rates were higher in earlier years; 2) whether AEs decreased over time; and 3) whether there was a substantial difference between the balloonassisted technique and the direct technique.

We think the higher $\mathrm{AE}$ rate could be explained by the higher rate of AEs in the earlier years of endoscopic ultrasound-guided gastroenterostomy (EUS$G E)$, since we included EUS-GE from the first cases performed in each participating center. All fatal AEs and $75 \%$ of stent misplacements occurred in one of the pioneering participating centers, soon after EUS-GE had been introduced. These events took place between March 2015 and May 2016. In this center, early cases were performed using the "overthe-guidewire" technique, before it was acknowledged that pushing the guidewire could cause the jejunum to move away from the stomach and result in stent misplacement [2]. The exact number of patients treated with this technique until it was abandoned could not be determined. In addition, increased experience with the use of lumen-apposing metal stents and more knowledge about procedural pitfalls and salvage techniques of EUS-GE might have resulted in improved outcomes in later years.

We acknowledge the importance of learning curves, but the limited number of procedures performed in each center did not allow for assessment of the effect of learning curves on outcomes after EUS-GE over time.
Two of the eight (25\%) stent misplacements were performed with the balloon-assisted technique and six (75\%) with the direct technique. In the 37 patients without stent misplacement, 30 (81\%) were performed with the direct technique and seven (19\%) with the balloon-assisted technique.

The second issue was regarding the role of EUS-GE as a first-line modality in management of malignant gastric outlet obstruction (GOO). We advocated duodenal stenting as the preferred treatment for patients with a life expectancy of less than 2 months, based on its favorable short-term outcomes but limited long-term patency [3]. It is minimally invasive and may carry less risks than EUSGE. In patients with a life expectancy of more than 2 months, surgical gastrojejunostomy (SGJ) is commonly performed as it provides better long-term patency than duodenal stenting [3]. We fully agree with McDonald and colleagues that in these patients and in expert hands, EUS-GE could provide an adequate and minimally invasive first-line alternative to SG]. While observational studies indicate that EUS-GE could be a promising new procedure for treating malignant GOO, randomized controlled trials (RCTs) are warranted to investigate the safety and durability of EUS-GE compared with SG], before implementing EUS-GE as first-line therapy in clinical practice. The ENDURO-study, a RCT comparing SGJ with EUS-GE that we plan to commence in 2021, is being designed to address this clinical question.

\section{Competing interests}

Prof. Dr. Vleggaar and Dr. Moons are consultants for Boston Scientific Corporation.

The authors

Janine B. Kastelijn, Leon M.G. Moons, Frank P. Vleggaar

Department of Gastroenterology and Hepatology, University Medical Center Utrecht, Utrecht, The Netherlands

\section{Corresponding author}

Frank P. Vleggaar, MD PhD

UMC Utrecht - Department of

Gastroenterology and Hepatology,

Heidelberglaan 100 Utrecht 3508 GA,

Netherlands

Fax: +0031887550724

f.vleggaar@umcutrecht.nl

\section{References}

[1] Kastelijn JB, Moons LMG, Garcia-Alonso FJ et al. Patency of endoscopic ultrasoundguided gastroenterostomy in the treatment of malignant gastric outlet obstruction. Endosc Int Open 2020; 8: E1194E1201

[2] Itoi T, Ishii K, Ikeuchi N et al. Prospective evaluation of endoscopic ultrasonographyguided double-balloon-occluded gastrojejunostomy bypass (EPASS) for malignant gastric outlet obstruction. Gut 2016; 65: 193-195

[3] Jeurnink SM, Steyerberg EW, van Hooft JE et al. Surgical gastrojejunostomy or endoscopic stent placement for the palliation of malignant gastric outlet obstruction (SUSTENT study): a multicenter randomized trial. Gastrointest Endosc 2010; 71: 490499 
Bibliography

Endoscopy International Open 2021; 09: E425-

E426

DOI 10.1055/a-1339-1459

ISSN 2364-3722

(c) 2021. The Author(s).

This is an open access article published by Thieme under the terms of the Creative Commons Attribution-NonDerivativeNonCommercial License, permitting copying and reproduction so long as the original work is given appropriate credit. Contents may not be used for commecial purposes, or adapted, remixed, transformed or built upon. (https:// creativecommons.org/licenses/by-nc-nd/4.0/)

Georg Thieme Verlag KG, Rüdigerstraße 14,

70469 Stuttgart, Germany

(ㄷ)(1) $\odot \ominus$ 